\title{
Evaluation of Relationship Between Canine Guided and Group Function Occlusion Schemes and Tooth Wear Along with Salivary Factors Such as Salivary Flow Rate and Salivary Ph- A Clinical Study
}

\author{
Dr. Shweta Tyagi ${ }^{1 *}$, Dr Manoj Kumar ${ }^{2}$, Dr. Sapna R
${ }^{1}$ Senior Lecturer, D. J Dental College Uttar Pradesh, India
${ }^{2}$ Professor, ITS-CDSR Muradnagar Uttar Pradesh, India \\ ${ }^{2}$ Professor, ITS-CDSR Muradnagar Uttar Pradesh, India
${ }^{3}$ Reader, ITS-CDSR Muradnagar Uttar Pradesh, India \\ ${ }^{4}$ Professor and Head, ITS-CDSR Muradnagar Uttar Pradesh, India \\ ${ }^{5}$ Professor, Teerthankar Dental College Uttar Pradesh, India \\ ${ }^{6}$ Senior Lecturer, ITS-CDSR Muradnagar Uttar Pradesh, India
}

\author{
DOI: $10.36348 /$ sjodr.2022.v07i01.009 \\ *Corresponding author: Dr. Shweta Tyagi \\ Senior Lecturer, D. J Dental College Uttar Pradesh, India
}

| Received: 11.12.2021 | Accepted: 23.01.2022 | Published: 28.01.2022

\section{Abstract}

Objective: To evaluate the relationship between canine guided and group function occlusion schemes and tooth wear along with salivary factors such as salivary flow rate and salivary $\mathrm{pH}$. Methodology: A cross sectional descriptive study was conducted among 50 subjects, 25 of group function and 25 of canine guided occlusion. Type of occlusion pattern and tooth wear was assessed through clinical intra-oral examination. Lateral excursive occlusion was determined with the aid of Shimstock to confirm tooth contact and the modified ordinal scale was used for evaluating tooth wear. Working side occlusal contact patterns were determined and classified into two groups: canine guided and group function. Unstimulated and stimulated whole saliva sample was collected to assess the $\mathrm{pH}$ and salivary flow rate. Data was analyzed using Statistical Package for Social Sciences (SPSS) version 21, IBM Inc. Descriptive data was reported for each variable. As the data was found to be normally distributed bivariate analyses was performed using Independent $t$ test. Level of statistical significance was set at p-value less than 0.05 Results: No significant difference was seen in $\mathrm{pH}$ when compared between canine guided and Group function occlusion as $\mathrm{p}>0.05$ whereas flow rate was found to be significantly more in group function. Conclusion: Most of tooth wear in canine guidance is reported in mandibular incisor followed by mandibular molar. No wear was seen in both maxillary and mandibular canines and minimal wear was reported in maxillary incisor. Type of occlusion did not affect the salivary $\mathrm{pH}$ rather it affected salivary flow rate.

Key words: Group function, canine guided occlusion, salivary $\mathrm{pH}$, salivary flow rate, and occlusion.

Copyright (C) 2022 The Author(s): This is an open-access article distributed under the terms of the Creative Commons Attribution 4.0 International License (CC BY-NC 4.0) which permits unrestricted use, distribution, and reproduction in any medium for non-commercial use provided the original author and source are credited.

\section{INTRODUCTION}

Occlusion is a key to a successful dental treatment and plays an important role in prosthodontic, restorative, orthodontic and periodontal treatment. There are numerous concepts, techniques, and philosophies concerning occlusion. In dentate patients most functional tooth contacts occur in a mandibular position slightly anterior to Centric Relation (CR), a position known as Centric Occlusion (CO) $[1,2]$.

This position can be recorded via one of the several registration methods and materials. The optimum occlusal scheme is mutually protected occlusion, in which the posterior teeth contact simultaneously and equally in $\mathrm{CO}$, the canine discludes the posterior teeth in lateral excursions and the anterior teeth disclude the posterior teeth in protrusion. So, over the years several concepts of dynamic occlusion have also been developed such as canine guided [3] and group function [4]. Canine guided and group function occlusion schemes are the common physiologic form of occlusion seen in natural dentate patient.

The canine guided occlusion can be defined as a form of mutually protected articulation in which the vertical and horizontal overlap of the canine teeth disengages the posterior teeth in excursive movement of the mandible, and the group function is defined as 
Shweta Tyagi et al; Saudi J Oral Dent Res, Jan 2022; 7(1): 45-53

multiple contact relations between the maxillary and mandibular teeth in lateral movements on the working side in which simultaneous contact of several teeth acts as a group to distribute occlusal forces [5].

There is no scientific evidence that supports one occlusal scheme over other. But some authors favour canine guidance over group function [8], claiming that the presence of canine guidance reduce the inter arch forces, and may therefore reduce normal tooth wear as well as parafunctional loads [6].

Patients can experience discomfort and sensitivity because of tooth wear: especially during drinking or tooth brushing [7]. If such teeth are left untreated then it may also lead to pain or loss of vitality [8]. The etiology of advanced tooth wear is of multifactorial character including factors such as functional or parafunctional habits, diet, diseases, saliva, bite force, craniofacial morphology, habitat and occupational environments [9]. The pattern of mandibular movements also has an association with tooth wear [10].

Saliva is one of the important physiological defence mechanisms that protects against erosive tooth wear [11]. Both quantity (flow rate) and quality of saliva $(\mathrm{pH})$ plays a role in the tooth wear process. It provides protection against acid erosion by different ways $[12,13]$.

Thus, present study was initiated with the aim to evaluate the relationship between canine guided and group function occlusion schemes and tooth wear along with salivary factors such as salivary flow rate and salivary $\mathrm{pH}$.

\section{METHODOLOGY}

The present cross sectional descriptive study was conducted in the Department of Prosthodontics and crown \& bridge, Ghaziabad. All the procedures were carried out in accordance with Declaration of HelsinkiEthical principles for medical research involving human subjects, 2013. (Ethical committee clearance no: ITSCDSR/IIHEC/2018-21/PROSTHO/06).

The total study population was of 50 subjects, 25 of group function and 25 of canine guided occlusion. Study population consisted of subjects ranging from 20-30 years with permanent dentition. Subjects with previous orthodontic treatment, occlusal adjustments, large restoration involving the incisal edge or cusp, crowns or fixed partial denture, gastro esophageal reflex, presence of clear sign of erosion or abrasion due to known causes and apparent pathologic periodontal problems were excluded.

Type of occlusion pattern and static occlusion, tooth wear was assessed through clinical intra-oral examination on a dental chair under direct vision.
Lateral excursive occlusion was determined with the aid of Shimstock to confirm tooth contact and the modified ordinal scale by Johanssen, Fareed, and Omar [13] was used as for evaluating tooth wear. Working side occlusal contact patterns were determined and classified into two groups: canine guided and group function.

Unstimulated whole saliva and stimulated whole saliva was collected. Before collection of saliva, the test tubes were pre weighed on weighing machine in research lab. The testing of salivary samples using $\mathrm{pH}$ meter and weighing machine was done at Advanced Research Center -I.T.S-CDSR, Ghaziabad. For the collection of unstimulated whole saliva subjects were advised to refrain from intake of any food or beverage (water exempted) one hour before the test session. Smoking, chewing gum and intake of coffee was also prohibited during this hour. The subject was advised to rinse his or her mouth several times with deionised water and then to relax for five minutes. The subject was then asked to make as little movements as possible and not to swallow, and to keep eyes open during collection periods.

For each subject, saliva was collected for one minute of practice trial and was discarded. A plastic or paper cup was used for this trial. The actual trial lasted for five minutes, and the sample was saved for further analysis.

For the collection of stimulated whole saliva the subject was instructed to sit motionless leaning the head forward over the funnel. The subject was instructed to chew the sugarless gum according to pace of about 70 strokes per minute. Every one minute the subject was asked to spit saliva into the test tube without swallowing. First two minute collection was discarded. Then, another three minute collection was saved for the analysis. The subject was then asked to spit everything into the tube after the last minute. The gum was removed from the funnel before weighing the tube and funnel with saliva.

The collected samples of saliva were taken to research lab in test tubes. The test tube with stimulated saliva was weighed on weighing balance. Similarly, test tube with unstimulated saliva was also weighed. Then, the $\mathrm{pH}$ of unstimulated saliva was measured by using $\mathrm{pH}$ meter in a beaker.

For calculation of salivary flow rate, following calculation was done:

Salivary flow rate $=($ post weight measure - pre weight measure $)$ Collection period

\section{STATISTICAL ANALYSIS}

Data was analyzed using Statistical Package for Social Sciences (SPSS) version 21, IBM Inc. 
Shweta Tyagi et al; Saudi J Oral Dent Res, Jan 2022; 7(1): 45-53

Descriptive data was reported for each variable. As the data was found to be normally distributed bivariate analyses was performed using Independent $t$ test. Level of statistical significance was set at p-value less than 0.05

\section{RESULTS}

Distribution according to grades of tooth wear among different teeth in subjects having canine guided occlusion and group function occlusion are given in Table 1. No significant difference was seen in $\mathrm{pH}$ when compared between canine guided and Group function occlusion as $\mathrm{p}>0.05$ whereas flow rate was found to be significantly more in group function in maxillary posteriors. No significant difference was seen in $\mathrm{pH}$ and flow rate when compared between canine guided and Group function occlusion as $\mathrm{p}>0.05$ in maxillary anteriors (Table 2). No significant difference was seen in $\mathrm{pH}$ when compared between canine guided and Group function occlusion as $\mathrm{p}>0.05$ whereas flow rate was found to be significantly more in group function in mandibular posteriors (Table 3). Comparative graphical illustration of $\mathrm{pH}$ and flow rate in different occlusion pattern and teeth in give in Graph 1.

Table-1: Distribution according to grades of tooth wear among different teeth in subjects having canine guided occlusion and group function occlusion

\begin{tabular}{|l|l|l|l|l|l|l|}
\hline & \multicolumn{2}{c|}{ Canine guided occlusion } & \multicolumn{2}{c|}{ Group function occlusion } \\
\hline & Grade 1 & Grade 2 & Grade 3 & Grade 1 & Grade 2 & Grade 3 \\
\hline & $\mathrm{N}$ & $\mathrm{N}$ & $\mathrm{N}$ & $\mathrm{N}$ & $\mathrm{N}$ & $\mathrm{N}$ \\
\hline & 0 & 5 & 0 & 0 & 16 & 2 \\
\hline Maxillary molar & 0 & 5 & 0 & 0 & 20 & 0 \\
\hline Maxillary premolar & 0 & 0 & 0 & 0 & 24 & 1 \\
\hline Maxillary canine & 0 & 1 & 0 & 0 & 9 & 0 \\
\hline Maxillary incisor & 0 & 8 & 0 & 0 & 16 & 3 \\
\hline Mandibular molar & 0 & 5 & 0 & 0 & 22 & 1 \\
\hline Mandibular premolar & 0 & 0 & 0 & 0 & 24 & 1 \\
\hline Mandibular canine & 0 & 0 & 0 & 0 & 11 & 0 \\
\hline Mandibular incisor & 0 & 9 & &
\end{tabular}

Table-2: Group wise comparison of $\mathrm{pH}$ and flow rate in maxillary posteriors and maxillary anteriors with tooth wear

\begin{tabular}{|c|c|c|c|c|c|c|c|c|c|}
\hline & & \multicolumn{4}{|c|}{ Maxillary posteriors } & \multicolumn{4}{|c|}{ Maxillary anteriors } \\
\hline & & Mean & $\begin{array}{l}\text { Std. } \\
\text { Deviation }\end{array}$ & $\begin{array}{l}\text { Std. Error } \\
\text { Mean }\end{array}$ & $\begin{array}{l}\mathrm{P} \\
\text { Value }\end{array}$ & Mean & $\begin{array}{l}\text { Std. } \\
\text { Deviation }\end{array}$ & $\begin{array}{l}\text { Std. } \\
\text { Error } \\
\text { Mean } \\
\end{array}$ & $\begin{array}{l}\mathrm{P} \\
\text { Value }\end{array}$ \\
\hline \multirow{2}{*}{$\mathrm{pH}$} & Canine Guided & 6.967 & .1500 & .0500 & \multirow{2}{*}{0.591} & 7.100 & . & . & \multirow[t]{2}{*}{0.699} \\
\hline & Group function & 7.013 & .2346 & .0479 & & 7.008 & .2308 & .0462 & \\
\hline \multirow{2}{*}{ Flow rate } & Canine Guided & .6733 & .17066 & .05689 & \multirow{2}{*}{$0.004 *$} & .9200 & $\cdot$ & 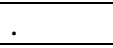 & \multirow{2}{*}{0.927} \\
\hline & Group function & .9513 & .24385 & .04978 & & .9428 & .24243 & .04849 & \\
\hline
\end{tabular}

Table-3: Group wise comparison of $\mathrm{pH}$ in mandibular posterior and mandibular anterior with tooth wear

\begin{tabular}{|c|c|c|c|c|c|c|c|c|c|}
\hline & & \multicolumn{4}{|c|}{ Mandibular posteriors } & \multicolumn{4}{|c|}{ Mandibular anteriors } \\
\hline & & Mean & $\begin{array}{l}\text { Std. } \\
\text { Deviation }\end{array}$ & $\begin{array}{l}\text { Std. Error } \\
\text { Mean }\end{array}$ & $\begin{array}{l}\mathrm{P} \\
\text { Value }\end{array}$ & Mean & $\begin{array}{l}\text { Std. } \\
\text { Deviation }\end{array}$ & $\begin{array}{l}\text { Std. Error } \\
\text { Mean }\end{array}$ & $\begin{array}{l}\mathrm{P} \\
\text { Value }\end{array}$ \\
\hline \multirow{2}{*}{$\mathrm{pH}$} & Canine Guided & 7.036 & .1433 & .0432 & \multirow[t]{2}{*}{0.758} & 7.078 & .1202 & .0401 & \multirow[t]{2}{*}{0.396} \\
\hline & Group function & 7.013 & .2346 & .0479 & & 7.008 & .2308 & .0462 & \\
\hline \multirow{2}{*}{$\begin{array}{l}\text { Flow } \\
\text { rate }\end{array}$} & Canine Guided & .6791 & .20067 & .06050 & \multirow{2}{*}{$0.003^{*}$} & .7733 & .13162 & .04387 & \multirow[b]{2}{*}{$0.015^{*}$} \\
\hline & Group function & .9513 & .24385 & .04978 & & .9428 & .24243 & .04849 & \\
\hline
\end{tabular}

Level of statistical significance $\mathrm{p}<0.05$ 


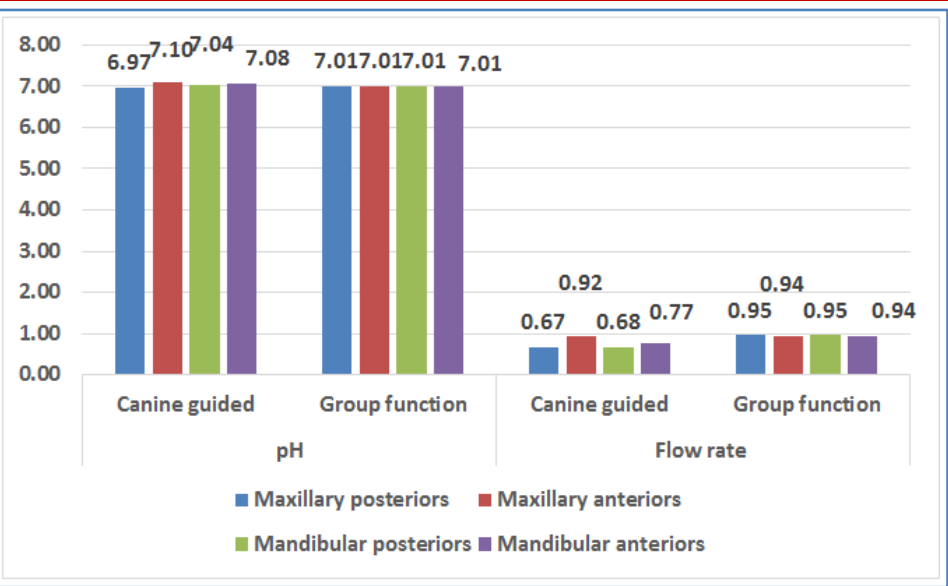

Graph-1: Comparative graphical illustration of $\mathrm{pH}$ and flow rate in different occlusion pattern and teeth

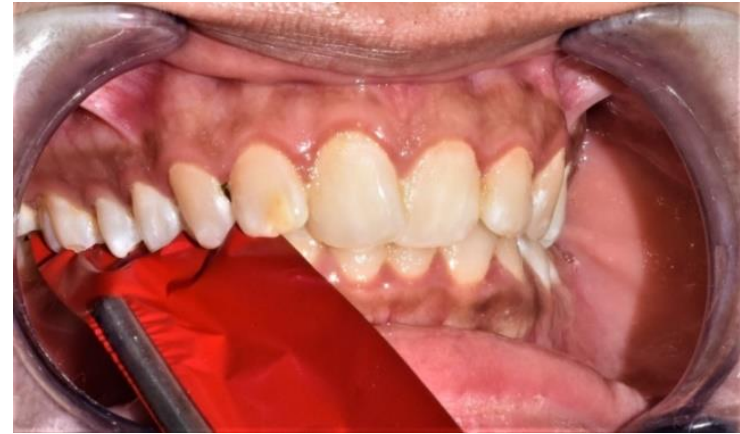

Fig-1: Checking occlusion on right side of subject with shimstock

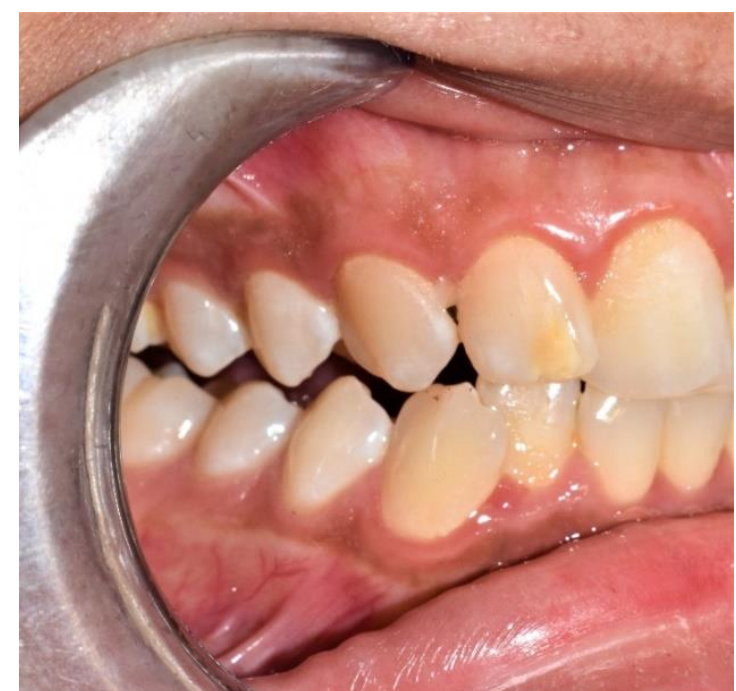

Fig-2: Marking showing Canine Guidance on right side of subject

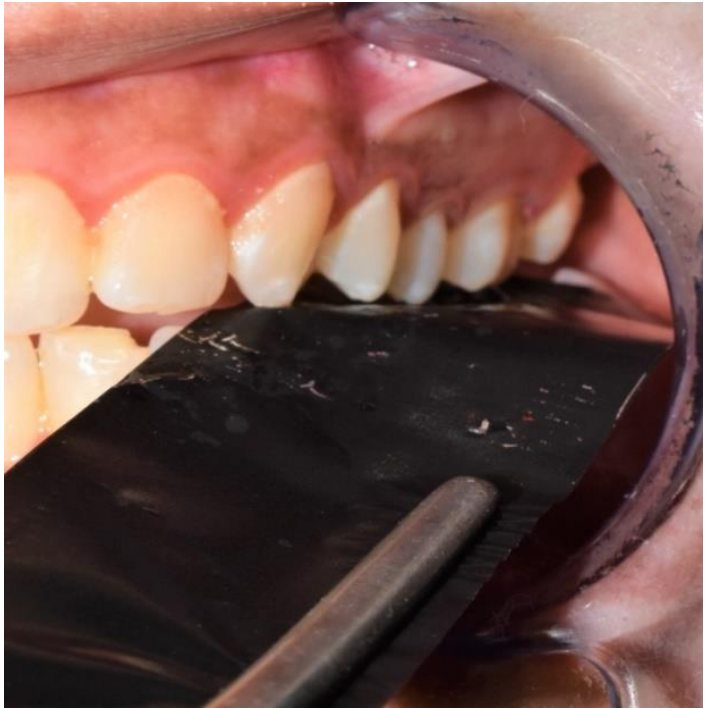

Fig-3: Checking occlusion on left side of subject with shimstock

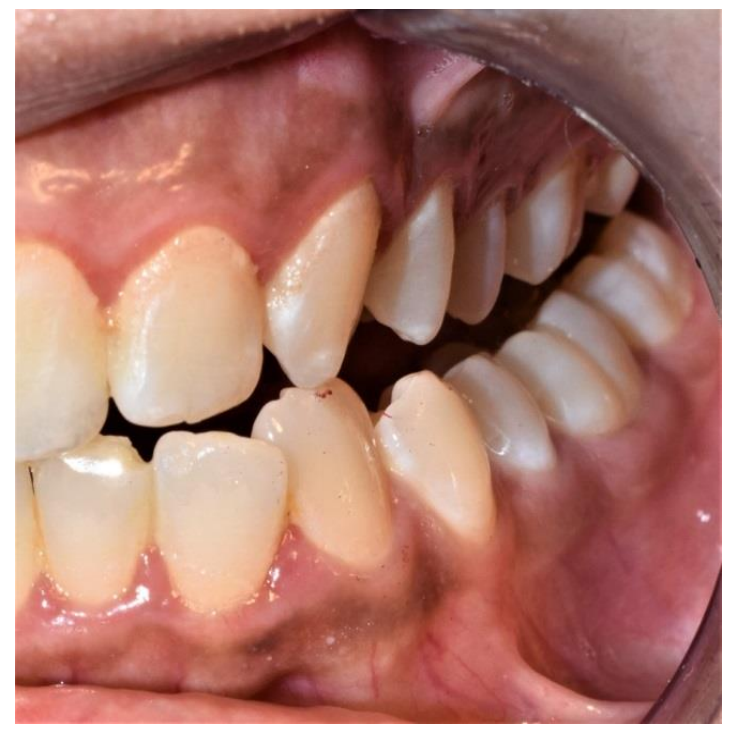

Fig-4: Marking showing Canine Guidance on left side of subject 


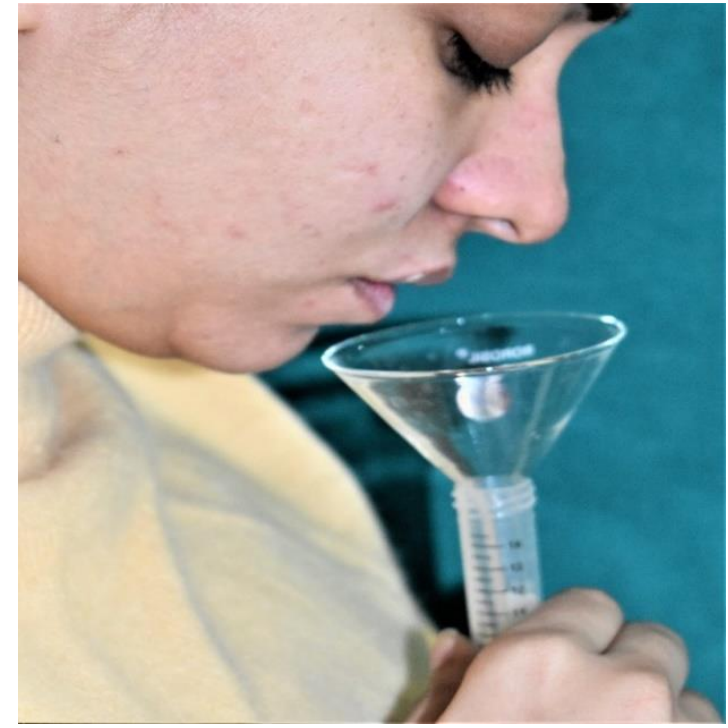

Fig-5: Collection of Saliva

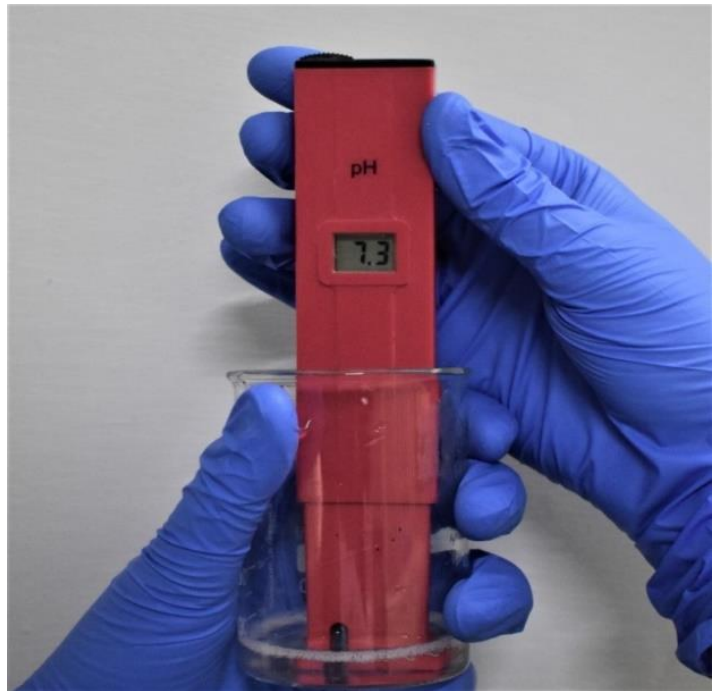

Fig-6: Measurement of $\mathrm{pH}$

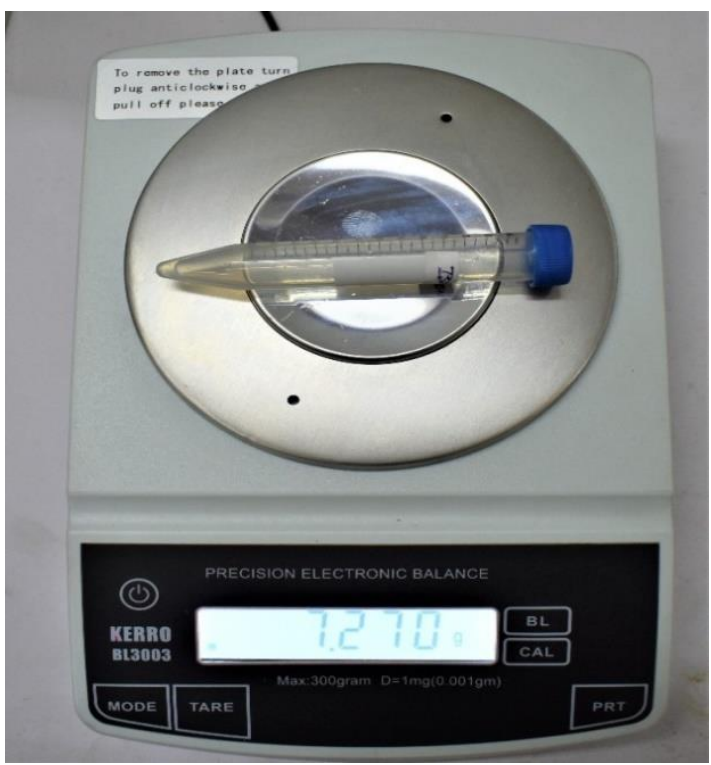

Fig-7: Weight of unstimulated saliva

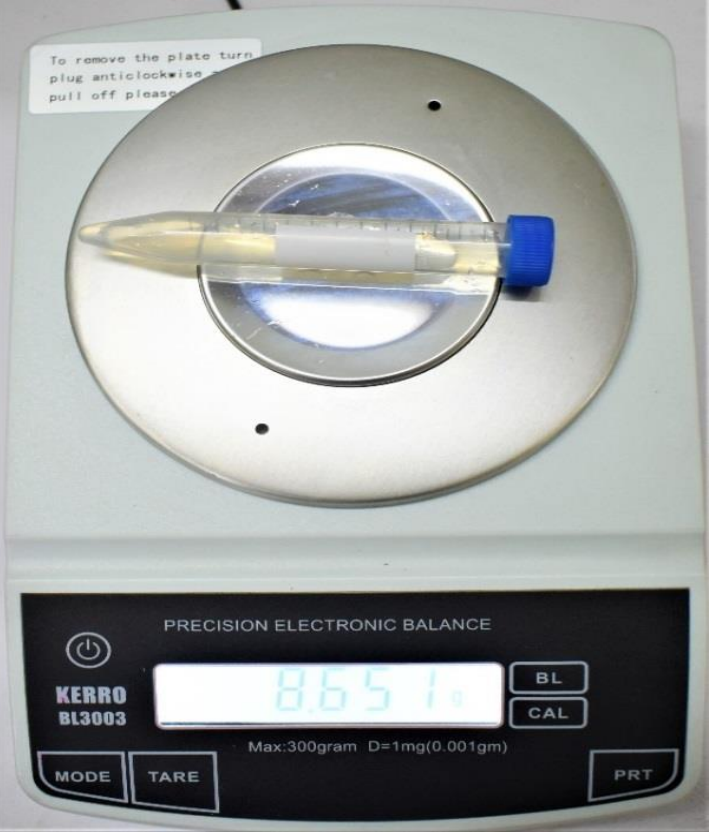

Fig-8: Weight of Stimulated Saliva

GROUP II: SUBJECT HAVING GROUP FUNCTION OCCLUSION

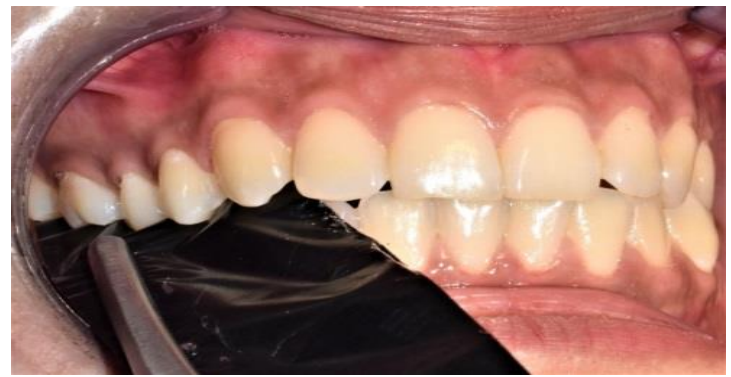

Fig-9: Checking Occlusion on right side of subject using Shimstock

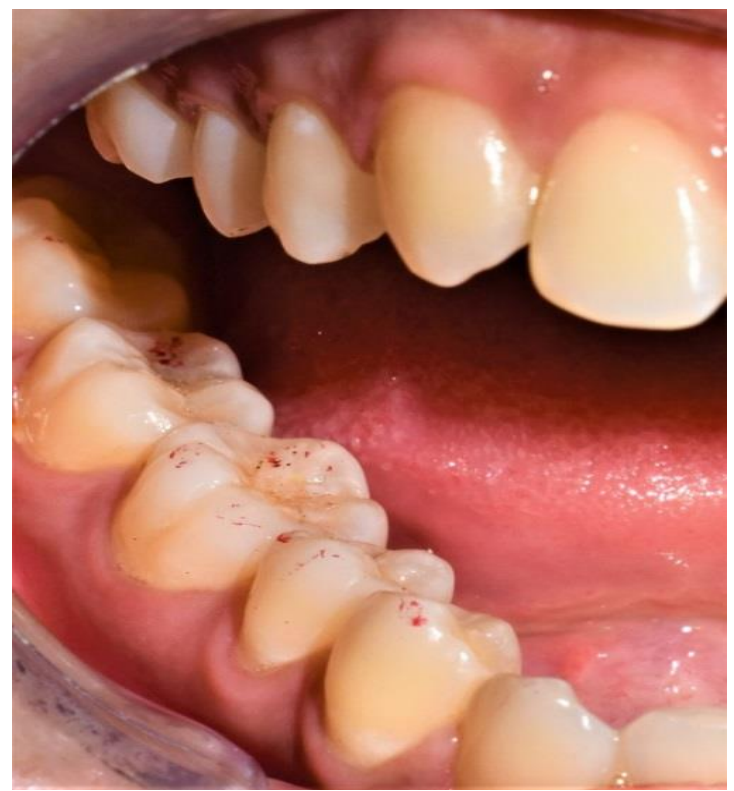

Fig-10: Marking showing Group Function on right side of subject 


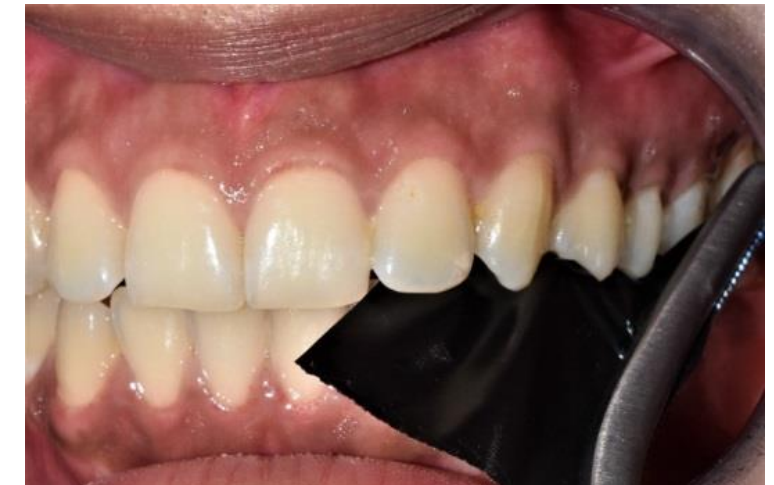

Fig-11: Checking Occlusion on left side of subject using Shimstock

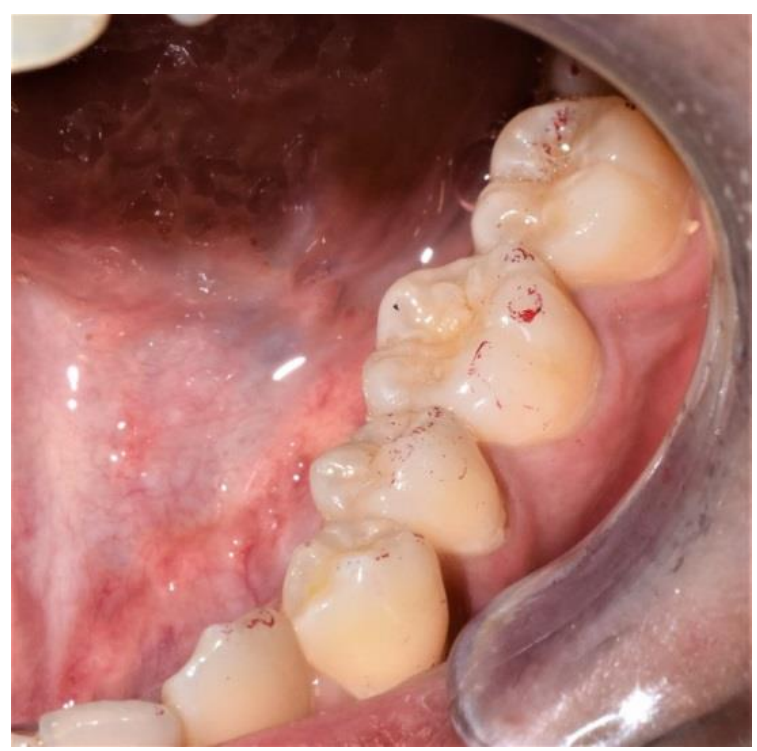

Fig-12: Marking showing Group Function on left side of subject

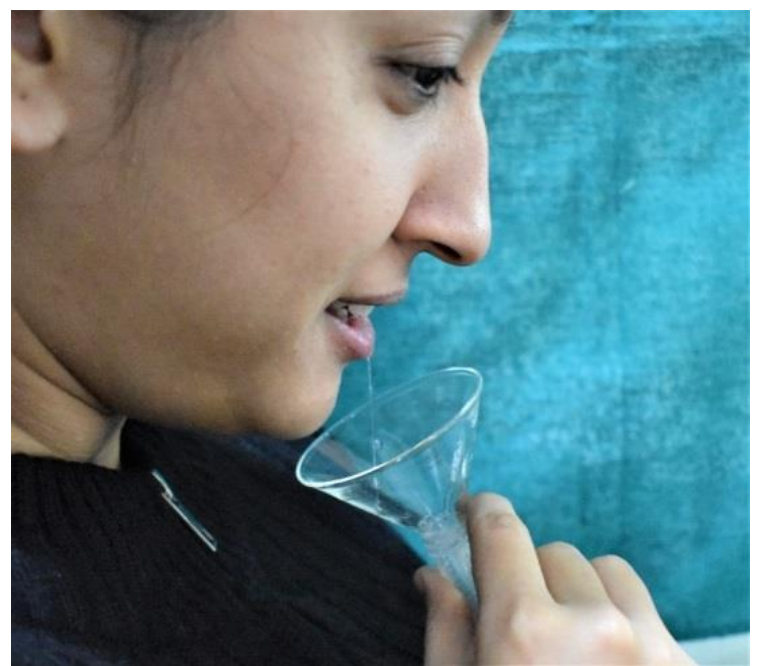

Fig-13: Collection of Saliva

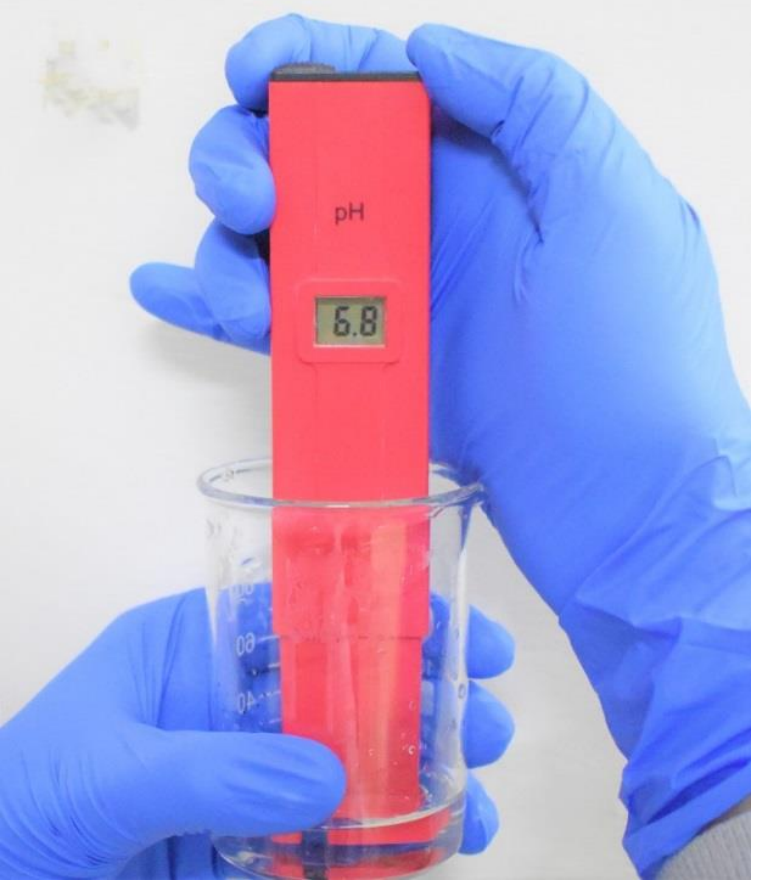

Fig-14: Measurement of $\mathrm{pH}$

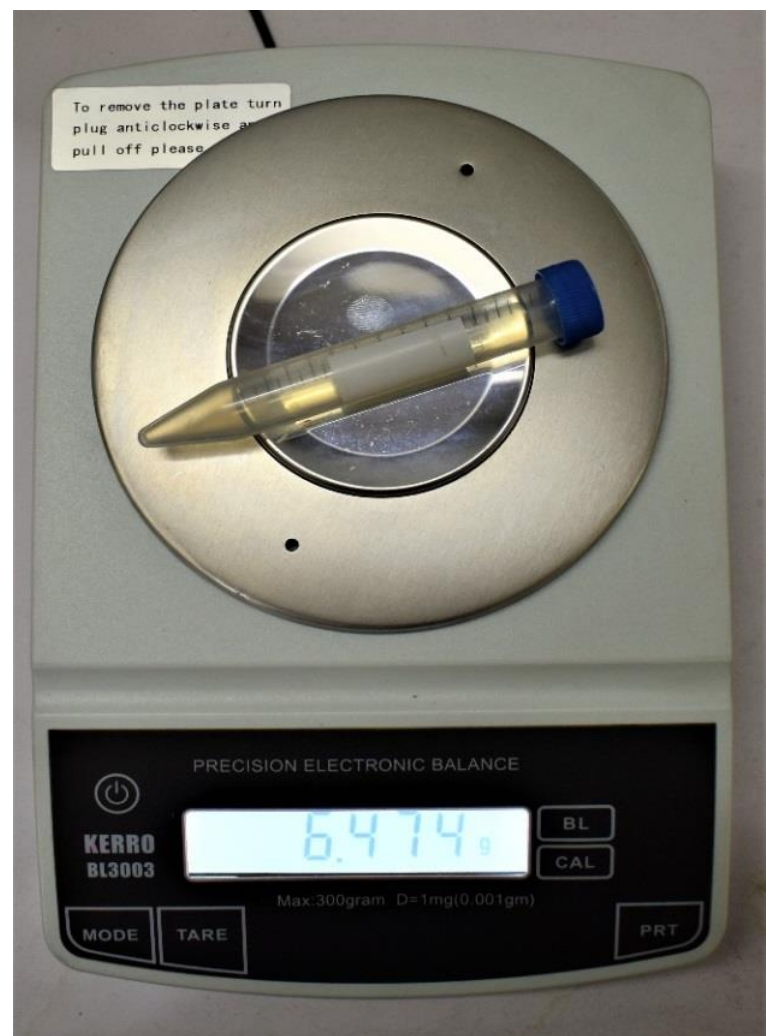

Fig-15: Weight of Unstimulated Saliva 


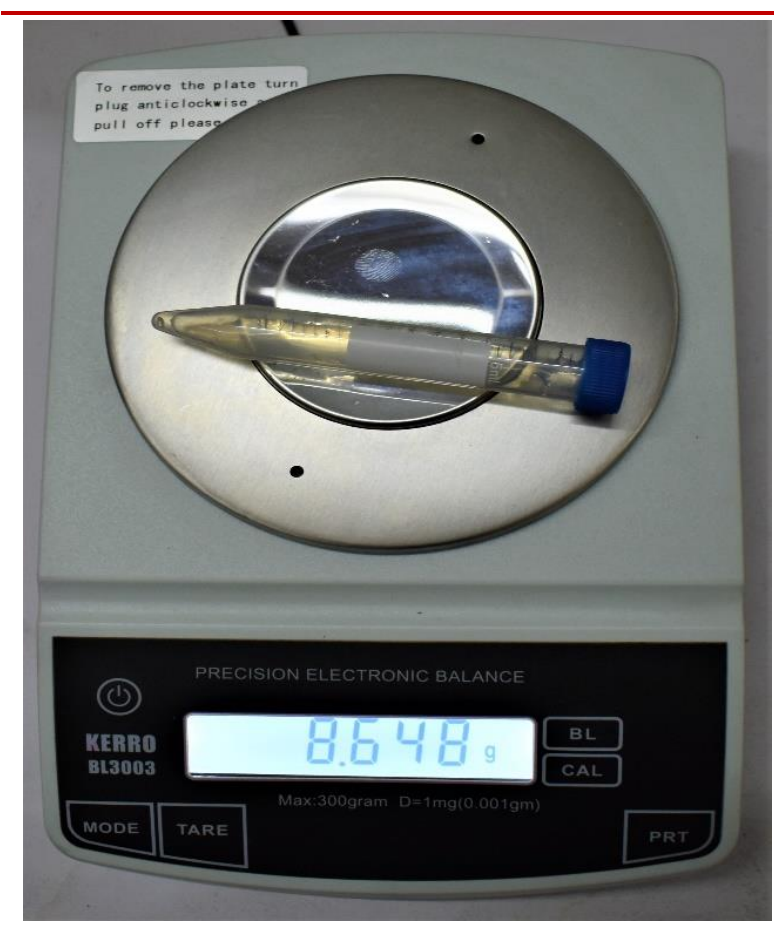

Fig-16: Weight of Stimulated Saliva

\section{DISCUSSION}

The essential part of all dental works in restorative dentistry is dental occlusion. Static and dynamic occlusal relationship can be altered by dental treatment while accomplishing as near ideal occlusion as possible. For dynamic occlusal relationships, there are three main concepts regarding tooth contact during the lateral excursion of mandibular movement i.e. balanced occlusion, canine guidance and group function [6].

Occlusion will be affected by every restoration, whether a simple amalgam filling or complex crown and bridgework. Therefore, planning of every restoration should be done so that adaptive tolerance of somatognathic system is not exceeded. Therefore to maintain harmony of the occlusal condition, the posterior teeth must pass close to but not contact their opposing teeth during mandibular movement [14]. Canine guidance or canine protection is also necessary for the protection of posterior teeth during excursive movements. Therefore, in this study tooth wear on two occlusal schemes i.e. canine guided and group function has been compared [14].

Now, as the age increases canine guidance is replaced by group function due to wear of canines. This change causes increase in wear in the posterior region [15]. Physiological wear causing vertical loss of enamel in a normal individual is approximately $0.02-0.04 \mathrm{~mm}$ a year [16], and wear is considered excessive when it causes aesthetic concerns to patient and causes symptoms of discomfort. Tooth wear in our study was measured according to Ordinal scale given by
Johansson, Fareed and Omar [13] in which grading is done on the basis of severity of tooth wear.

In Holland, Woltgens et al. [17] documented salivary parameters in 11 patients with idiopathic erosion and compared them with age matched controls. Unstimulated salivary flow rates were extremely low in erosion susceptible group. Saliva is essential for the maintenance of oral health and decreased salivary flow causes a clinically significant oral imbalance. Furthermore, diminished saliva production reduces the capacity to clear and neutralize dietary acids in the mouth contributing to erosive lesions in some individuals.

In current study most of the tooth wear was reported in group function as compared to canine guidance. These findings correlate with the study of Sandra et al. [18] and Butler et al. [19] in which tooth wear in canine guidance among $38.5 \%$ patients and in group function among $61.5 \%$ patients was reported. This is due to the fact that canine guidance reduces the lateral tooth contact and possibility of interfering contacts [20].

According to Sandra et al. [18] most of the tooth wear in canine guidance was reported in lower first premolar $(26.7 \%)$ and no wear in lower first and second molar. In group function most wear was reported in lower first premolar $(32 \%)$ and no wear in lower second molar. But in the present study the results are different from the study of Sandra et al. [18]. Most wear in canine guidance is reported in mandibular incisor (36\%) followed mandibular molar (32\%). In group function, maximum wear was reported in maxillary and mandibular canines $(96 \%)$ and minimum wear was seen in maxillary incisors $(36 \%)$. Also, grade 2 wear was seen maximum in mandibular molars $(12 \%)$. This difference is due to occurrence of interferences in different teeth, food intake, occupational hazards and other wear types (attrition, erosion, abrasion) which varies in different population.

On examining the severity of tooth wear it was observed that grade 0 and grade 1 were the most prevalent, similar to findings by Abdullah et al. [21] So, this study found a significant correlation between physiologic type of occlusal schemes and occlusal tooth wear. This is similar to a study in Netherland by Spijker et al. [22], but in contrast to other studies that found no significant correlation between the type of occlusal schemes and tooth wear.

The relation of $\mathrm{pH}$ to tooth wear in both canine guided and group function was not found to be significant. Its explanation can be derived from the study of Hara et al. [23] which stated no clear correlation between saliva properties $(\mathrm{pH}$, buffer capacity) and the susceptibility of enamel to demineralization. 
In contrast to findings of $\mathrm{pH}$, salivary flow rate was found to be significantly corelated to tooth wear in canine guided and group function in maxillary posteriors $(p=0.004)$, mandibular posteriors $(p=0.003)$ and mandibular anteriors $(0.015)$.

Maxillary anteriors had a non-significant $(p=0.927)$ relation to tooth wear in canine guided and group function population. Also the flow rates were higher in group function subjects. Buzalaf et al. [24] in 2012 has discussed the fact that tests of the stimulated and unstimulated flow rate and buffering capacity of saliva may provide some information about the susceptibility of an individual to tooth wear.

However, it has to be kept in mind that these parameters are only two of a multifactorial condition. Studies have shown that sour diet has a strong influence on the anticipatory salivary flow, which can be significantly increased when compared with the normal unstimulated flow rate. Salivary flow may also to be reduced in cases of vigorous exercise due to dehydration that may be induced by enhanced elimination of body fluids. Association between sport activities and tooth wear has been reported [25]. The cause could be direct acid exposure or strenuous exercise, which may increase gastroesophageal reflux. Also, swimmers exercising in water have a low $\mathrm{pH}$ and athletes who frequently consume sports drinks have increased risk to develop lesions.

So, in our study no specific correlation of salivary $\mathrm{pH}$ and flow rate to tooth wear in canine guided and group function occlusion was found but tooth wear in canine guidance and group function occlusion was significantly correlated and wear in group function subjects was more compared to canine guided subjects.

There are several lacunae or gaps in our knowledge of correlation of salivary factors with occlusion and tooth wear. In this study, several factors such as type of wear (attrition, erosion, abfraction etc.), dietary habits, physical activities etc. we're not specified. These factors may change the outcome of the study. Hence, there is scope for further research in this area.

\section{CONCLUSION}

Within the limitations of this study following conclusions were drawn:

1. Most of tooth wear in canine guidance is reported in mandibular incisor $(36 \%)$ followed by mandibular molar (32\%). No wear was seen in both maxillary and mandibular canines and minimal wear $(4 \%)$ was reported in maxillary incisor.

2. In group function, maximum wear was reported in maxillary and mandibular canines (96\%) and minimum wear was observed in maxillary incisors $(36 \%)$.

\section{REFERENCES}

1. Asawaworarit, N., \& Mitrirattanakul, S. (2011). Occlusal scheme in a group of Thais. The journal of advanced prosthodontics, 3(3), 132-135.

2. Davies, S., \& Gray, R. M. J. (2001). What is occlusion?. British dental journal, 191(5), 235245.

3. D'Amico, A. (1961). Functional occlusion of the natural teeth of man. The Journal of prosthetic dentistry, 11(5), 899-915.

4. Beyron, H. (1964). Occlusal relations and mastication in Australian aborigines. Acta odontologica scandinavica, 22(6), 597-678.

5. The glossary of prosthodontic terms. (2005). J Prosthet Dent, 94(1); 10-92.

6. Clark, J. R., \& Evans, R. D. (1998). Functional occlusal relationships in a group of postorthodontic patients: preliminary findings. The European Journal of Orthodontics, 20(2), 103110.

7. Khalifa, N., Allen, P. F., Abu-bakr, N. H., AbdelRahman, M. E., \& Abdelghafar, K. O. (2012). A survey of oral health in a Sudanese population. BMC Oral Health, 12(1), 1-9.

8. Daly, R. W. R., Bakar, W. Z., Husein, A., Ismail, N. M., \& Amaechi, B. T. (2010). The study of tooth wears patterns and their associated aetiologies in adults in Kelantan, Malaysia. Arch Orofac Sci, 5(2), 47-52.

9. Sanhouri, N. M., Ziada, H. M., Ahmed, G. I., \& Kamis, A. H. (2010). Tooth surface loss, prevalence and associated risk factors among 12 14 years school children in Khartoum State, Sudan. Community dental health, 27(4), 206-212.

10. Abdullah, A., Sherfudhin, H., Omar, R., \& Johansson, A. (1994). Prevalence of occlusal tooth wear and its relationship to lateral and protrusive contact schemes in a young adult Indian population. Acta Odontologica Scandinavica, 52(4), 191-197.

11. Johansson, A. K., Omar, R., Carlsson, G. E., \& Johansson, A. (2012). Dental erosion and its growing importance in clinical practice: from past to present. International journal of dentistry, 2012.

12. Hannig, M., \& Balz, M. (1999). Influence of in vivo formed salivary pellicle on enamel erosion. Caries research, 33(5), 372-379.

13. Johansson, A., Fareed, K., \& Omar, R. (1994). Lateral and protrusive contact schemes and occlusal wear: a correlational study in a young adult Saudi population. The Journal of prosthetic dentistry, 71(2), 159-164.

14. The envelope of function. (2007). In, Dawson PE (ed.), Functional occlusion from TMJ to smile design. Mosby Elsevier, 141-8.

15. David, K., \& Bhat, K. M. (2012). Prevalence Of Tooth Wear In Patients Attending The Department of Periodontics, Manipal College of Dental 
Sciences, Manipal. National journal of integrated research in Medicine, 3(2).

16. Lambrechts, P., Braem, M., Vuylsteke-Wauters, M., \& Vanherle, G. (1989). Quantitative in vivo wear of human enamel. Journal of dental research, 68(12), 1752-1754.

17. Woltgens, J. H., Vingerling, P., de BlieckHogervorst, J. M., \& Bervoets, D. J. (1985). Enamel erosion and saliva. Clinical preventive dentistry, 7(3), 8-10.

18. Palomino-Gómez, S. P., Jeremias, F., Finoti, L. S., Paredes-Coz, G., \& Raveli, D. B. (2011). Influence of lateral excursion on vestibular cervical dental abfraction. Acta Odontológica Latinoamericana, 24(3), 283-288.

19. Butler, R. J., \& Bernstein, I. S. (1974). Canine role in dental wear patterns: Macaca nemestrina. American journal of physical anthropology, 40(3), 391-395.

20. Luther, F. (1998). Orthodontics and the temporomandibular joint: where are we now? Part
1. Orthodontic treatment and temporomandibular disorders. The Angle Orthodontist, 68(4), 295-304.

21. Abdullah, A., Sherfudhin, H., Omar, R., \& Johansson, A. (1994). Prevalence of occlusal tooth wear and its relationship to lateral and protrusive contact schemes in a young adult Indian population. Acta

Odontologica Scandinavica, 52(4), 191-197.

22. Van't Spijker, A., Rodriguez, J. M., Kreulen, C. M., Bronkhorst, E. M., Bartlett, D. W., \& Creugers, N. H. (2009). Prevalence of tooth wears in adults. Int J Prosthodont, 22(1), 35-42.

23. Hara, A. T., \& Zero, D. T. (2014). The potential of saliva in protecting against dental erosion. Erosive tooth wear, 25, 197-205.

24. Buzalaf, M. A. R., Hannas, A. R., \& Kato, M. T. (2012). Saliva and dental erosion. Journal of Applied Oral Science, 20, 493-502.

25. Mulic, A., Tveit, A. B., Songe, D., Sivertsen, H., \& Skaare, A. B. (2012). Dental erosive wear and salivary flow rate in physically active young adults. BMC oral health, 12(1), 1-8. 